\title{
Feds target redundancies and waste at Health Canada
}

$\mathrm{T}$ hink of it as spring cleaning. Colocation, shared administra"wasteful practices" are the core elements of the Conservative government's strategy to reduce federal health expenditures.

The budget, unveiled Mar. 29 by Finance Minister Jim Flaherty, will see cuts in health department spending to the tune of $\$ 309.9$ million by fiscal 2014/15, some \$200.6 million of which will be achieved through measures aimed at "enhancing coordination, consolidating operations and eliminating redundant activities" at Health Canada (www.budget.gc.ca/2012/plan/pdf/Plan 2012-eng.pdf).

It's part of a broader scheme to achieve savings through "eliminating waste in the internal operations of government, making it leaner and more efficient," Finance Minister Jim Flaherty stated in his budget speech (www.budget .gc.ca/2012/rd-dc/speech-eng.pdf).

But critics are skeptical such savings can be achieved solely through a "backoffice" shuffle.

"I'm hard pressed to see how that sort of money is going to come from consolidation of some services," says Patty Ducharme, national executive vicepresident for the Public Service Alliance of Canada. "With Health Canada, what can you consolidate that's not going to have a massive impact on the services that are delivered to Canadians?"

Pamela Fralick, president and CEO of the Canadian Healthcare Association, concurs. The government should have provided a more detailed account of where and how cuts will be made, she says. "I want the itemized documentation of where these cuts are coming from because $\$ 200.6$ million is a lot of money. Is it an entire department? Is it a program? Is it attrition only, which still concerns me, by the way, but would preserve some programs?"

"If there are inefficiencies, absolutely let's find them," she adds. "But we don't know [from looking at the budget]

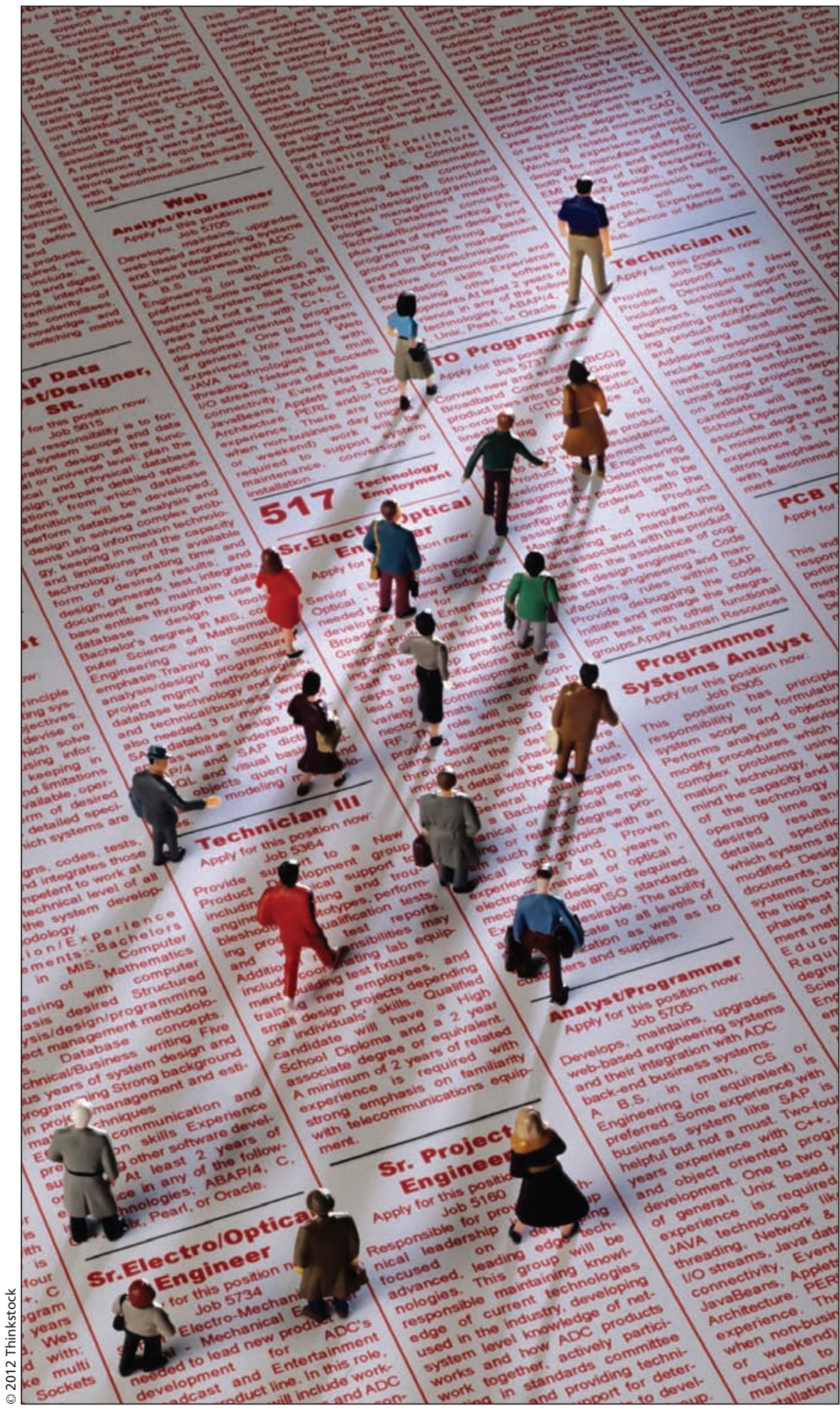

Canadian Finance Minister Jim Flaherty estimates that 19200 of 400000 civil servants will be looking for jobs as a result of the spending review exercise that will trim $\$ 5.2$ billion from the federal budget over three years. 
whether this is a deliberate number and behind it is a very accurate assessment of necessary efficiencies."

Health Canada and the Public Health Agency of Canada (PHAC) will adopt a shared services model aimed at "eliminating duplication and overlap between their respective organizations through the consolidation of internal services and the standardization of policies and processes," the budget states. Under that arrangement, they will also "transform how they manage grants and contributions to achieve administrative efficiencies and generate savings."

But further details of the marriage are yet to be determined.

The Canadian Food Inspection Agency (CFIA) will similarly merge its back-office functions with Agriculture and Agri-Food Canada in a bid to "integrate scientific research capacity and expertise through colocation and collaboration."

The government's action plan also proposes to provide $\$ 51.2$ million over the next two years for CFIA to continue collaboration with Health Canada and PHAC to implement measures to "enhance surveillance and early detection and improve response capabilities to food-borne illness emergencies."

Originally introduced by government in 2009, those measures include:
- hiring new food safety staff, including 70 inspectors to focus on readyto-eat meat facilities

- providing $24 / 7$ availability of health risk assessment teams to improve support to food safety investigations

- improving coordination between federal and provincial departments and agencies

- improving communications to vulnerable populations before and during a food-borne illness outbreak

- improving tracking of potential outbreaks through a national surveillance system

- expanding government's ability to test for food-borne illnesses to enable a more rapid response to outbreaks, and

- initiating a third-party audit of the food inspection system.

In the 2011/12 budget, CFIA received $\$ 100$ million over five years for "targeted investments in inspector training, additional science capacity, and electronic tools to support the work of frontline inspectors."

As part of its new action plan, CFIA will overhaul how it monitors and enforces food labelling regulations, as well as introduce a Web-based tool to enable consumers to report food safety concerns directly to companies. Government will also repeal regulations related to food container standards to enable industry to take advantage of new packaging formats and technologies.

In other efforts to streamline federal health activities, the government will introduce legislation to wind down Assisted Human Reproduction Canada, the regulatory agency created in 2006 to promote the safety, health and rights of Canadians using reproductive technologies. The agency, which is slated for closure Mar. 31, 2013, is "no longer justified" in the wake of the 2010 Supreme Court of Canada ruling that substantially reduced federal authority over assisted human reproduction (http://scc.lexum.org/en/2010/2010scc 61/2010scc61.html). Health Canada will assume responsibility for the agency's remaining federal functions, such as compliance and enforcement.

The department will also enhance its regional presence in the North by opening offices in Iqaluit and Yellowknife to deliver services locally rather than from Ottawa.

All told, the spending reduction measures will trim $\$ 111.7$ million from the health portfolio in 2012/13. Those savings will grow to $\$ 218.5$ million in 2013/14 and to $\$ 309.9$ million by $2014 / 15$. Lauren Vogel, CMAJ

CMAJ 2012. DOI:10.1503/cmaj.109-4175 